\title{
Comparing The Patients' Throughput in An Emergency Department in Tabriz City With International Standards
}

\section{Seyed Hossein Ojaghi Haghighi', Samad Shams Vahdati', Mahsa Sharifi Namin², Sonya Sharifi Namin², Paria Habibollahi ${ }^{3}$, Akram Mikaeilpour ${ }^{4}$}

${ }^{1}$ Emergency Department, Tabriz University Of Medical Science, Tabriz/iran

${ }^{2}$ Faculty Of Medicine, Tabriz University Of Medical Science, Tabriz/iran

${ }^{3}$ Faculty Of Pharmacy, Tabriz University Of Medical Science, Tabriz/iran

${ }^{4}$ Member Of European Society Of Cardiology

Yazışma Adresi / Corresponding to:

Yrd. Doç. Dr. Samad Shams Vahdati, No1, Gholestan2, Pezeshkan Alley, Abrasani Street Tabriz - Iran

Tel: 00984116581401 Mail: sshamsv@gmail.com

Introduction: Emergency department (ED) patients'throughput includes all the processes that patients go through; this study was designed to investigate the patients throughput and the duration of stay in this department.

Methods: In a prospective cross-sectional study, we evaluated the association between workflow process and admission duration in emergency department of Sina hospital of Tabriz from March 20th to July 20th 2011.

Result: We studied 800 randomly selected patients referred to the emergency department between 20th March and 20th July 2011. The mean time duration between first visit and disposition was $64.94 \pm 64.7 \mathrm{~min}$ (mode $=24 \mathrm{~min}$ ). The most prevalent chief complaint was common cold in which was presented in 448 patients

Discussion: In the management of emergency department, all of parts must work as a member of team and if one of these members has a problem and does not work properly then pass-through will be happen.

Keywords: emergency department, throughput, standards 


\section{Introduction}

Emergency department (ED) patients'throughput includes all the processes that patients go through from the moment they enter the ED until the determination of their final disposition and indicates the time that the patient should stay in the emergency department.

These processes typically consists of triage/reception, placement in ED beds, initial nursing examination, physician evaluation, diagnostic testing, treatment measures, consultantsand determination of final status of the patient ${ }^{1}$.

The performance quality of the above mentioned processes can be controlled by some measurements. Measurements include the times needed for each process mentioned above, these also consist of the diagnostic testing turn-around-times (TATs) determined by the time between requesting a diagnostic test and achievement of its result by the physician².

Various studies have been conducted regarding the length of stay in the emergency department and emergency workflow in normal and overcrowded conditions and every factors involved in prolongation of the ED stay such as triage, reception, imaging, laboratory and etc. ${ }^{3-11}$.

In a recent study on the patients' length of stay in the newly founded emergency department in Imam Reza EducationalMedical and Research Center of Tabrizl Iran, the time between initial reception and first physician visit was investigated ${ }^{12}$.

Considering the recent establishment of the technical emergency department in the Sina Educational- Medical Center of Tabriz, and in order to be informed about the management process of the ED patients and comparing it with the international standards to improve the workflow of the patients, this study was designed to investigate the patients throughput and the duration of stay in this department.

\section{Materials and Methods:}

In a prospective cross-sectional study, we evaluated the association between workflow process and admission duration in emergency department of Sina hospital of Tabriz from March 20th to July 20th 2011. Patients were randomly entered in this study.All the patients were visited by emergency medicine specialist or assistant. We measured the intervals between referring, admission, visit, doing nursing process and final disposition. Duration between requested modalities by physician like laboratory tests, $\mathrm{X}$-ray and achieving the results was recorded also, and the data were collected.

\section{Statistical Analysis \& Ethical Considerations:}

Statistical analysis was performed by SPSS software package version 15.0 for windows (SPSS Inc., Chicago, USA). Quantitative data were presented as mean \pm standard deviation (SD), while qualitative data were demonstrated as frequency and percent (\%). All participants have signed a written consent which was kept completely secret, and the study protocol was approved by the Ethics Committee of Tabriz University of Medical Sciences (TUMS), which was in compliance with Helsinki Declaration.

\section{Results:}

We studied 800 randomly selected patients referred to the emergency department between 20th March and 20th July 2011. 16 patients were excluded because of leavingED without prior informing.

376 patients (48\%)were male and $408(52 \%)$ were female. The mean age of the patients was $34.37 \pm 20.9$ years old (188 years old) (mode $=24)$. The mean time duration between arrival admission in emergency department was $3.21 \pm 6.6$ $\min ($ mode $=5 \mathrm{~min}$ ).

The mean time duration between first visit and disposition was 64.94 $\pm 64.7 \mathrm{~min}$ (mode= $24 \mathrm{~min}$ ). Laboratory tests were requested for 126 patients, in which mean time duration between request and achievement results was $35.29 \pm 23.7$ min (mode $=30 \mathrm{~min}$ ). $X$ ray was requested for 104 patients, in which mean time duration between request and achievement results was $33.15 \pm 31.1 \mathrm{~min}$ (mode $=30 \mathrm{~min}$ ). The most prevalent chief complaint was common cold in which was presented in 448 patients.

88 patients (11.22\%) referred to ED with drug intoxication. Intoxicated patients had the longest time of stay in the ED(table 1). $608(77.5 \%)$ patients were discharged after treatment and 
144 (18.4\%) patients were hospitalized. The remnant 32 patients $(4.1 \%)$ were referred to other centers for other required modalitiesor hospitalization

\section{Discussion:}

The patients' throughput includes all the process that patients go through from the time they enter the ED until the final disposition and it indicates their length of stay in the ED ${ }^{7,13}$. The process of workflow in the ED is started by triage and reception and the acceptable time for this process is $5-8$ minutes $^{14}$.

In research series by Partoiee et al, conducting triage by the physician and targeted application of point of care laboratory tests resulted in significant reduction of waiting time of patients and the overall staying time in the ED and the amount of patients who left the ED without physician visit also decreased significantly but led to significant increasing of medical costs instead $^{15,16,17}$

The reception and registration processes are the important stages of the patient throughput which typically should take less than 10-12 minutes form the moment of patient arrival ${ }^{14}$.

According to the studies by Gorelick et al, bedside reception of the patients can reduce the patients' length of stay in the $E D^{18}$. In our ED, the process of triage and reception is conducted continuously with meantime of3.21 minutes (mode=5) which is in the acceptable range of mentioned standards. The presence of the nurse on the bedside of the patient and primary examination should not last more than 15 minutes from the time of the non-critical patient entry ${ }^{19}$, while in our study the overall mean time was 14.37 minutes (mode=2). However, the time dispersion in this study is differentand varies from 0 minutes (at moment of entry) to 160 minutes; because nurses quickly attend for high risk patients in critical situations, but for the non-urgent cases and under conditions such as overcrowding, nursing evaluation would be postponed.

The initial physician evaluation of the critical patientsshould be conducted by the time from the patient arrival and in case of non-critical patient this should take no longer than 20 minutes $^{14}$. In the conducted study, the mean time duration between entry and physician attendance by patient bedside is
7.327 minutes (mode $=0$ ) which indicates that most of the evaluationsoccurred on the ED arrival.

Other stages of patient throughput in emergency department are the diagnostic testing turn-around-times. Studies on laboratory performance of the 690 hospitals have considered the improvement of the throughput times of the patients associated with the quality of sample management in labs and the rate of sample transfer ${ }^{20}$.

In some other researchesit has been suggested,applying thepoint of caretesting significantly reduce the patients' length of stay in the ED $21,22,23$. In our study, the lab test TATs was 35.29 minutes (mode $=30$ ) and the mean time of the $x$-ray TATs was $32.15 \mathrm{~min}$ (mode=30). In a center with appropriate facilities and resources, it is expected that the test and $x$-ray results become available for the physician in less than $30 \mathrm{mi}-$ nutes $^{24}$

The maximum predicted length of stay in an ED with satisfactory resources for non-urgent patients without requesting diagnostic tests is 60-70 minutes but a patient receiving laboratory and radiology servicesrequires 90-110 minutes $^{1}$. In our study the meantime duration of stayin ED was 64.94 minutes (mode $=25$ ). One of the reasons could be lack of fast-track and lack of appropriate triage. This indicates inefficiency of the emergency department in separating critical from nonurgent patients because the maximum length of stay in our ED is $300 \mathrm{~min}$.

\section{Conclusion:}

In the management of emergency department, all of parts must work as a member of team and if one of these members has a problem and does not work properly then pass-through will be happen. Before setting the emergency department, we must consider all of sides and all of pass-through. 


\section{References}

1. ACEP Crowding Resources Task Force. Responding to Emergency Department Crowding: A Guidebook for Chapters. American College of Emergency Physicians; 2002.

2. Knickman JR, Lipkin M Jr, Finkler SA, Thompson WG, Kiel J. The potential for using non-physicians to compensate for the reduced availability of residents. Acad Med 1992;67:429-38.

3. Sylvester R. NHS faces another bleak winter, says Millburn. The Daily Telegraph 2000; Nov 4.

4. Gibbs N. "Do you want to die?" The crisis in emergency care is taking its toll on doctors, nurses-and patients. Time 1990;135:58-60, 62-5.

5. Doherty L. Crowded hospitals diverting patients. The Syndney Morning Herald 1998; Mar 11.

6. Derlet R, Richards J, Kravitz R. Frequent overcrowding in U.S. emergency departments. AcadEmerg Med 2001;8:151-5.

7. Andrulis DP, Kellermann A, Hintz EA, Hackman BB, Weslowski VB. Emergency departments and crowding in United States teaching hospitals. Ann Emerg Med 1991;20:980-6.

8. McCabe JB. Emergency department overcrowding: a national crisis. Acad Med 2001;76:672-4.

9. Henry M. Overcrowding in America's emergency departments: inpatient wards replace emergency care. AcadEmerg Med 2001;8:188-9.

10. Kellermann AL. Déjà vu. Ann Emerg Med 2000;35:83-5.

11. Partovi et al. Faculty triage shortens emergency department length of stay. AcadEmerg Med. 2001; 8(10): 990-995.

12. Amiri H, Shamsvahdati S, Ghodrati N,Taghizadieh A,Mahmoodivar S,Foroughi M,Nehzati A. The Length of Waiting for First Visit and Disposition in Emergency Department in Tabriz Imam Reza Hospital. Turk J Emerg Med 2008;8(4):160-163

13. Emergency Department Management: principles and application/ Editorin-chief, Richard F Salluzzo et al. Mosby-year book; Inc. 1997; 21: 201-205.
14. Strauss and Mayer's Emergency Department Management. Robert W. Strauss and Thom A. Mayer, 2013, MC Graw Hill.

15. Miró $O$, Antonio $M T$, Jiménez $S$, De Dios $A$, Sánchez $M$, Borrás $A$, et al. Decreased health care quality associated with emergency department overcrowding. Eur J Emerg Med 1999;6:105-7.

16. Lynn SG, Kellermann AL. Critical decision making: managing the emergency department in an overcrowded hospital. Ann Emerg Med 1991;20:287-92.

17. Schull MJ, Slaughter PM, Redelmeier DA. Urban emergency department overcrowding: defining the problem and eliminating misconceptions. CJEM 2002;4:76-83.

18. Gorelick MH, Yun HJ. The effect of in-room registration on emergency department length of stay. Ann Emerg Med. 2005; 45: 128-133.

19. Emergency Department Management: principles and application/ Editorin-chief, Richard F Salluzzo et al. Mosby-year book; Inc. 1997; 31: 256-258.

20. DeBehnke D, O'Brien S, Leschke R. Emergency medicine resident work productivity in an academic emergency department. AcadEmerg Med 2000;7:90-2.

21. Salazar A, Corbella X, Onaga $H$, Ramon R, Pallares $R$, Escarrabill J. Impact of a resident strike on emergency department quality indicators at an urban teaching hospital. AcadEmerg Med 2001;8:804-8.

22. Gerbeaux P, Ledoray V, Liauthaud H, Torro D, Takun K, Thirree R, et al. Medical student effect on emergency department length of stay. Ann Emerg Med 2001;37:275-8.

23. Chan L, Kass LE. Impact of medical student preceptorship on ED patient throughput time. Am J Emerg Med 1999;17:41-3.

24. Krochmal P, Riley TA. Increased health care costs associated with ED overcrowding. Am J Emerg Med 1994;12:265-6. 